\title{
A new application to one-step nucleic acid amplification-discarded sample in breast cancer: Preliminary results
}

\author{
CAROLINA RIBEIRO ${ }^{1}$, INÊS GANTE ${ }^{2}$, MARGARIDA FIGUEIREDO DIAS $^{2}$, \\ ANA GOMES $^{3}$ and HENRIQUETA COIMBRA SILVA ${ }^{1,4}$
}

\author{
${ }^{1}$ Institute of Medical Genetics/UC Genomics, Faculty of Medicine, University of Coimbra, 3000-548 Coimbra; \\ ${ }^{2}$ University Clinic of Gynecology and ${ }^{3}$ Department of Pathology, Coimbra Hospital and University Centre (CHUC), \\ 3000-075 Coimbra; ${ }^{4}$ Coimbra Institute for Clinical and Biomedical Research-Center of Investigation on Environment, \\ Genetics and Oncobiology (iCBR-CIMAGO), Faculty of Medicine, University of Coimbra, 3000-548 Coimbra, Portugal
}

Received February 5, 2021; Accepted June 7, 2021

DOI: $10.3892 / \mathrm{mco} .2021 .2380$

\begin{abstract}
The one-step nucleic acid amplification (OSNA) assay is a molecular method used for detecting breast cancer (BC) metastasis in sentinel lymph nodes (SLNs). However, this method has a major disadvantage, since it prevents tissue structure analysis, while only one molecular marker can be evaluated, namely cytokeratin 19 mRNA. The aim of the present study was to evaluate whether an OSNA-discarded sample could be suitable for the gene expression analysis of the SLN microenvironment. The remaining intermediate phase of the centrifuged SLN homogenate obtained from the OSNA assay of samples from two patients with BC was used for mRNA extraction. Subsequently, the expression of five genes, namely forkhead box, cluster of differentiation 4 and three control genes, was determined by reverse transcription-quantitative PCR analysis. The results demonstrated that high-quality RNA was extracted. Therefore, this RNA may be used for gene expression analyses to predict novel molecular biomarkers associated with immuno-inflammatory microenvironment.
\end{abstract}

\section{Introduction}

Sentinel lymph node (SLN) biopsy is the standard approach used for the locoregional staging of patients with clinically T1-T2 invasive breast cancer (BC) with clinically negative axillae (1). Unfortunately, the conventional intraoperative histological examination of frozen SLN sections has been associated with a false-negative result rate of $10-30 \%$ for metastasis (2). To overcome this issue, an increasing number of centers have adopted a novel molecular approach, namely

Correspondence to: Professor Henriqueta Coimbra Silva, Institute of Medical Genetics/UC Genomics, Faculty of Medicine, University of Coimbra, Pólo III, Azinhaga de Santa Comba, Celas, 3000-548 Coimbra, Portugal

E-mail: hsilva@fmed.uc.pt

Key words: breast cancer, sentinel lymph node, one-step nucleic acid amplification, biomarkers, microenvironment the one-step nucleic acid amplification (OSNA) assay (2-5). OSNA is based on reverse transcription loop-mediated isothermal amplification to quantify the content of tumor cells in the whole SLN homogenate via evaluating the mRNA expression of cytokeratin (CK)19 $(2,3)$. The OSNA assay has several advantages, as it assures the analysis of all SLNs and is a semi-quantitative, reproducible, rapid and standardized method (2-5).

Another study supported the accuracy of the OSNA assay for the staging of other types of cancer (6). A drawback of this approach is that none of the tissue can be left for subsequent examination. Consequently, it is impossible to carry out tissue structure analysis or assessment of other biological markers (7-9). Furthermore, several rare false-negative results may also occur in cancers with decreased CK19 expression. In 2016, Martin-Sánchez et al (10) suggested that OSNA samples could be suitable for DNA molecular studies, including the assessment of gene promoter methylation.

The aim of the present study was to verify whether the OSNA-discarded samples could be used in gene expression profiling studies of the SLN microenvironment in order to assess host immunoinflammatory responses.

\section{Materials and methods}

Sample processing. Informed consent was obtained from all participants, as recommended by the local Ethics Committee of the Coimbra Hospital and University Centre (CHUC; Coimbra, Portugal) according to the principles outlined in the Declaration of Helsinki (ethics approval no. CHUC-045-20). The OSNA-remaining lysates from two patients (samples 1 and 2) were randomly selected from samples preserved at $-80^{\circ} \mathrm{C}$ at the Department of Pathology of CHUC. Both patients suffered from stage I ductal invasive luminal A BC with a clinically negative axilla. SLNs were identified through a combination of techniques, using patent blue and radioisotopes or superparamagnetic iron oxide, according to the established department guidelines. After the extranodal tissue was removed, all fresh SLNs were homogenized in $4 \mathrm{ml}$ Lynorhag ${ }^{\circledR}$ solution (Sysmex Corporation) using a Polytron ${ }^{\circledR}$ PT1300D homogenizer (Kinematica AG). Briefly, 
$1 \mathrm{ml}$ homogenate was centrifuged at $10,000 \mathrm{x}$ for $1 \mathrm{~min}$ at room temperature and $\sim 500 \mu \mathrm{l}$ of the intermediate phase were collected. A volume of $20 \mu \mathrm{l}$ of the intermediate phase was used for the OSNA assay utilizing the Lynoamp ${ }^{\mathrm{TM}} \mathrm{BC}$ kit on the RD-100i system (Sysmex Corporation). The remaining volume was kept at $-20^{\circ} \mathrm{C}$ for subsequent experiments.

Tsujimoto et al (3) determined the cut-off values for the OSNA assay, suggesting that CK19 mRNA copies/ $\mu 1<250$ indicated the absence of micrometastasis. Herein, based on the calculated number of CK19 mRNA copies/ $\mu 1$, no metastasis was observed in either SLN.

Furthermore, a total of $3 \mathrm{ml}$ peripheral blood was collected from a healthy volunteer in an EDTA tube, which served as a positive control for the gene expression analysis. Subsequently, peripheral blood mononuclear cells (PBMCs) were isolated by density gradient centrifugation. Briefly, blood was slowly added to a conical tube containing $3 \mathrm{ml}$ Ficoll-Paque ${ }^{\mathrm{TM}}$ Plus solution (Cytiva) using a polyethylene transfer pipet. The tube was then centrifuged at $800 \mathrm{x}$ g for $20 \mathrm{~min}$ at room temperature. Following centrifugation, mononuclear cells at the interface were carefully harvested and transferred into a $1.5-\mathrm{ml}$ microtube. Subsequently, half of the mononuclear cell suspension was centrifuged at $8,000 \mathrm{x} \mathrm{g}$ for $5 \mathrm{~min}$ at room temperature, the supernatant was discarded, and the pellet was resuspended in $300 \mu \mathrm{l} \mathrm{NR}$ buffer (NZYTech, Lda.) supplemented with $1 \% \beta$-mercaptoethanol (Sigma-Aldrich; Merck KGaA), and preserved at $-20^{\circ} \mathrm{C}$.

Total RNA was extracted from PBMCs using the NZY Total RNA Isolation kit (NZYTech, Lda.), with a DNase decontamination step, according to the manufacturer's instructions.

The OSNA-remaining intermediate phase was subjected to a DNA decontamination step, including the incubation of $87.5 \mu \mathrm{l}$ of the OSNA-remaining intermediate phase with $10 \mu \mathrm{l}$ DNase and $2.5 \mu \mathrm{l}$ digestion buffer for $15 \mathrm{~min}$ at room temperature. Subsequently, a total of $100 \mu \mathrm{l}$ of the aforementioned solution was subjected to an RNA clean-up protocol using the NZY Total RNA Isolation kit. Briefly, $350 \mu 1 \mathrm{NR}$ buffer was added to the sample followed by mixing. Then, the sample was supplemented with $250 \mu 196 \%$ ethanol followed by mixing using a pipette. The solution was then transferred to a spin column placed in a 2-ml collection tube and centrifuged at room temperature for $15 \mathrm{sec}$ at $\geq 8,000 \mathrm{x} \mathrm{g}$. The steps were carried out according to the RNA extraction protocol. Finally, $30 \mu \mathrm{l}$ RNAse-free water was added to the column to elute RNA. The eluted RNA was quantified using a NanoDrop-1000 spectrophotometer (Thermo Fisher Scientific, Inc.). RNA integrity and quality (IQ score) were assessed using the Qubit ${ }^{\mathrm{TM}}$ RNA IQ Assay (Thermo Fisher Scientific, Inc.) on a Qubit ${ }^{\mathrm{TM}} 4$ Fluorometer (Invitrogen; Thermo Fisher Scientific, Inc.).

Reverse transcription-quantitative PCR analysis. The expression of three housekeeping control genes, namely $\beta 2$-microglobulin (B2M), glyceraldehyde-3-phosphate dehydrogenase (GAPDH) and ribosomal protein S18 (RPS18), and that of two genes particularly expressed in lymphocytes, namely forkhead box P3 (FOXP3) and cluster of differentiation (CD4), were analyzed. Total RNA from each sample $(2 \mu \mathrm{g})$ was reverse-transcribed into cDNA using the Omniscript RT kit (Qiagen $\mathrm{GmbH}$ ) and random hexamer primers in a $20-\mu 1$ reaction volume according to the manufacturer's instructions. The resultant cDNA was amplified using the primers listed in Table I. Amplification specificity was verified by Sanger sequencing. qPCR was performed with a $20-\mu 1$ reaction mixture containing $2 \mu 1$ cDNA, $0.15 \mu \mathrm{M}$ of each primer, and $1 \mathrm{X} \mathrm{iQM}^{\mathrm{TM}} \mathrm{SYBR}^{\circledR}$ Green Supermix (Bio-Rad Laboratories, Inc.). Amplifications were carried out on the CFX96 Touch Real-Time System (Bio-Rad Laboratories, Inc.) under the following thermocycling conditions: One cycle at $95^{\circ} \mathrm{C}$ for $5 \mathrm{~min}$ followed by 40 cycles at $95^{\circ} \mathrm{C}$ for $30 \mathrm{sec}$ (denaturation), annealing (the corresponding temperatures are listed in Table I) for $30 \mathrm{sec}$ and $72^{\circ} \mathrm{C}$ for $30 \mathrm{sec}$ (extension). To verify the absence of DNA contamination, RNA was directly subjected to qPCR and no amplification curve was detected.

Statistical analysis. Three replicates were performed for each sample. Data are presented as mean \pm SD. Student's independent t-test was used to compared mRNA concentrations and IQ scores. $\mathrm{P}<0.05$ was considered to indicate statistically significant differences. The statistical package SPSS (version 19.0, IBM SPSS Statistics for Windows; IBM Corp.) was used to perform the statistical analysis.

\section{Results}

The RNA concentration, integrity and quality values, as well as the RT-qPCR $\mathrm{C}_{\mathrm{q}}$ values, are summarized in Table II. Although the concentrations of mRNA were statistically significantly different among the three samples $(\mathrm{P}<0.01)$, values obtained for OSNA sample 1 and the control sample (PBMCs) were very similar (1.2 difference). In addition, the high IQ values (7-8.8) indicated that the samples mainly contained large or tertiary structured RNA ( $>80 \%)$. Although the mRNA concentration of OSNA sample 2 was more than 3 times higher compared with that of the other samples, it exhibited a lower IQ score $(\mathrm{P}<0.05)$, indicating that this sample consisted of a higher quantity of small and degraded RNA, which was consistent with the $\mathrm{C}_{\mathrm{q}}$ values obtained in the RT-qPCR analysis. The RT-qPCR amplification plots are shown in Fig. 1.

\section{Discussion}

Lymph nodes are considered as the main escape route for tumor cells from the primary site to other regions of the body. Therefore, the evaluation of lymph nodes is crucial for the prognosis of BC (1). Currently, the OSNA assay is commonly used in clinical practice to detect macro- and micrometastasis in early-stage BC with clinically negative axillae $(4,5)$. In addition, other potential applications of the OSNA assay are under investigation (6). However, this diagnostic method, in its current form, cannot be used in SLN microstructural studies, and these studies could provide useful information regarding immune responses and tumor aggressiveness (7-9). Therefore, improving the prognostic value of OSNA may have a major impact on the risk stratification of patients with cancer.

The present study suggested that OSNA-discarded samples may be suitable for further gene expression analyses 
Table I. List of primer sequences used for quantitative PCR analysis.

\begin{tabular}{|c|c|c|c|}
\hline Gene (accession no.) & Primer sequence $\left(5^{\prime} \rightarrow 3^{\prime}\right)$ & Amplicon size (bp) & Annealing $\mathrm{T}\left({ }^{\circ} \mathrm{C}\right)$ \\
\hline B2M (NM_004048.4) & $\begin{array}{l}\text { F: GCATCATGGAGGTTTGAAGATG } \\
\text { R: TAAGTTGCCAGCCCTCCTAGAG }\end{array}$ & 234 & 60 \\
\hline GAPDH (NM_002046.7) & $\begin{array}{l}\text { F: AAGGTGAAGGTCGGAGTC } \\
\text { R: CCTGGAAGATGGTGATGG }\end{array}$ & 229 & 56 \\
\hline RPS18 (NM_022551.3) & $\begin{array}{l}\text { F: GCAGACATTGACCTCACC } \\
\text { R: CTTCTTCAGTCGCTCCAG }\end{array}$ & 207 & 56 \\
\hline CD4 (NM_001382706.1) & $\begin{array}{l}\text { F: CCATTTCTGTGGGCTCAGGT } \\
\text { R: TCAGCTTGGATGGACCTTTAGT }\end{array}$ & 290 & 59 \\
\hline FOXP3 (NM_014009.4) & $\begin{array}{l}\text { F: CACATTTCATGCACCAGCTCT } \\
\text { R: TTGAGGGAGAAGACCCCAGT }\end{array}$ & 133 & 59 \\
\hline
\end{tabular}

$\mathrm{F}$, forward primer; $\mathrm{R}$, reverse primer; bp, base pair; $\mathrm{T}$, temperature; $B 2 M, \beta 2$-microglobulin; $G A P D H$, glyceraldehyde-3-phosphate dehydrogenase; RPS18, ribosomal protein $\mathrm{S} 18 ; C D 4$, cluster of differentiation 4 ; FOXP3, forkhead box $\mathrm{P} 3$.

Table II. RNA concentration, integrity and quality and Cq values.

\begin{tabular}{lccc}
\hline Variables & OSNA 1 & OSNA 2 & PBMCs \\
\hline RNA, mean \pm SD & & & \\
Concentration $(\mu \mathrm{g} / \mu \mathrm{l})$ & $79.4 \pm 2.8$ & $255 \pm 3.6$ & $7 \pm 0.25$ \\
IQ value & $8.8 \pm 0.21$ & & $8 \pm 0.31$ \\
$\mathrm{C}_{\mathrm{q}}$ from qPCR & & 21.83 & 15.75 \\
B2M & 19.35 & 24.71 & 18.79 \\
GAPDH & 20.82 & 26.34 & 20.70 \\
RPS18 & 20.72 & 26.12 & 21.78 \\
CD4 & 21.83 & 32.20 & 29.30 \\
FOXP3 & 29.47 & & \\
\hline
\end{tabular}

OSNA, one-step nucleic acid amplification; IQ, integrity and quality assessed with Qubit ${ }^{\mathrm{TM}}$ RNA IQ assay; qPCR, quantitative PCR; Cq, quantification cycle; $B 2 M, \beta 2$-microglobulin; $G A P D H$, glyceraldehyde-3-phosphate dehydrogenase; RPS18, ribosomal protein S18; $C D 4$, cluster of differentiation 4 ; FOXP3, forkhead box P3.

of the SLN microenvironment. RNA quality and integrity play a key role in qPCR experiments (11). The results of the present study demonstrated that the IQ score for one of the RNA samples was higher compared with the control sample (PBMCs). It is often impossible to design RNA-specific primers for gene expression profiling studies. Therefore, it would be useful to include a DNA decontamination step, as was performed in the present study. Furthermore, the RT-qPCR analysis results further verified the feasibility of this method.

It has been suggested that a thorough selection of reference genes for the normalization of gene expression is crucial. Therefore, according to the current Minimum Information for Publication of Quantitative Real-Time PCR Experiment guidelines, the use of more than one reference gene is recommended for all qPCR analyses (12). Herein, three commonly used housekeeping genes, namely $R P 18 S$, $G A P D H$ and $B 2 M$, were assessed. To perform quantification of gene expression, namely using the $2^{-\Delta \Delta \mathrm{Cq}}$ method (13), experiments with OSNA-positive and OSNA-negative samples must be performed to select the most suitable reference genes.

In addition to evaluating metastasis, SLNs are also considered as natural targets for studying tumor-immune system interactions. Therefore, in the present study, two genes, namely $C D 4$ and $F O X P 3$, were analyzed. CD4 is a glycoprotein expressed on the surface of immune cells, such as T helper cells, monocytes, macrophages and dendritic cells. In addition, CD4 is highly expressed in PBMCs and lymph nodes (13). FOXP3 is a regulatory T-cell lineage-specific transcription factor, consequently exhibiting reduced expression in PBMCs $(14,15)$.

Martin-Sánchez et al (10) demonstrated that the OSNA-remaining homogenate could be used in DNA-based studies, particularly in methylation analysis. The authors revealed an association between the hypermethylation of the Ras association domain family member 1 gene and macrometastasis, micrometastasis and the number of isolated tumor cells in BC SLNs, suggesting that the prognostic value of the OSNA assay could be improved. 

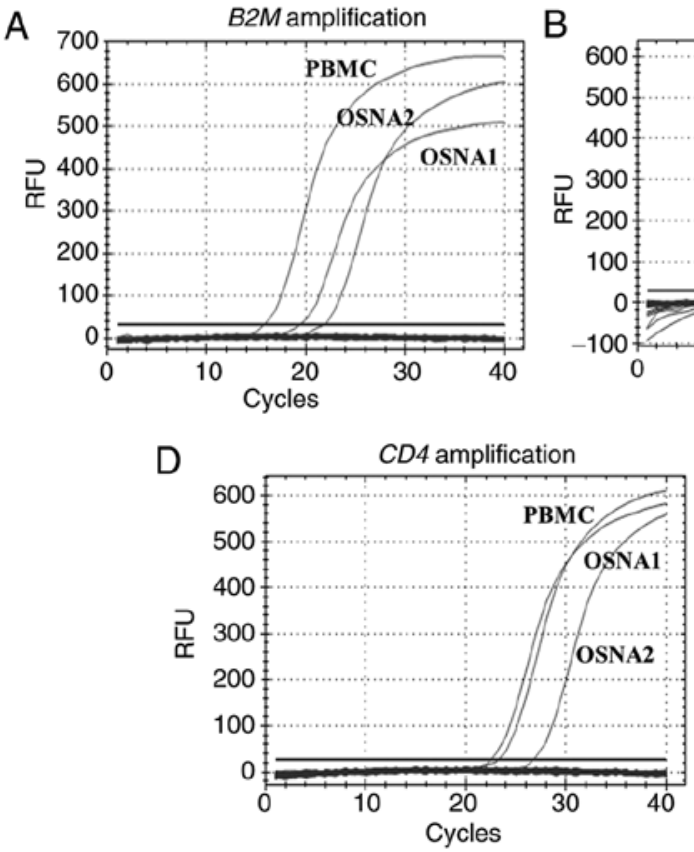
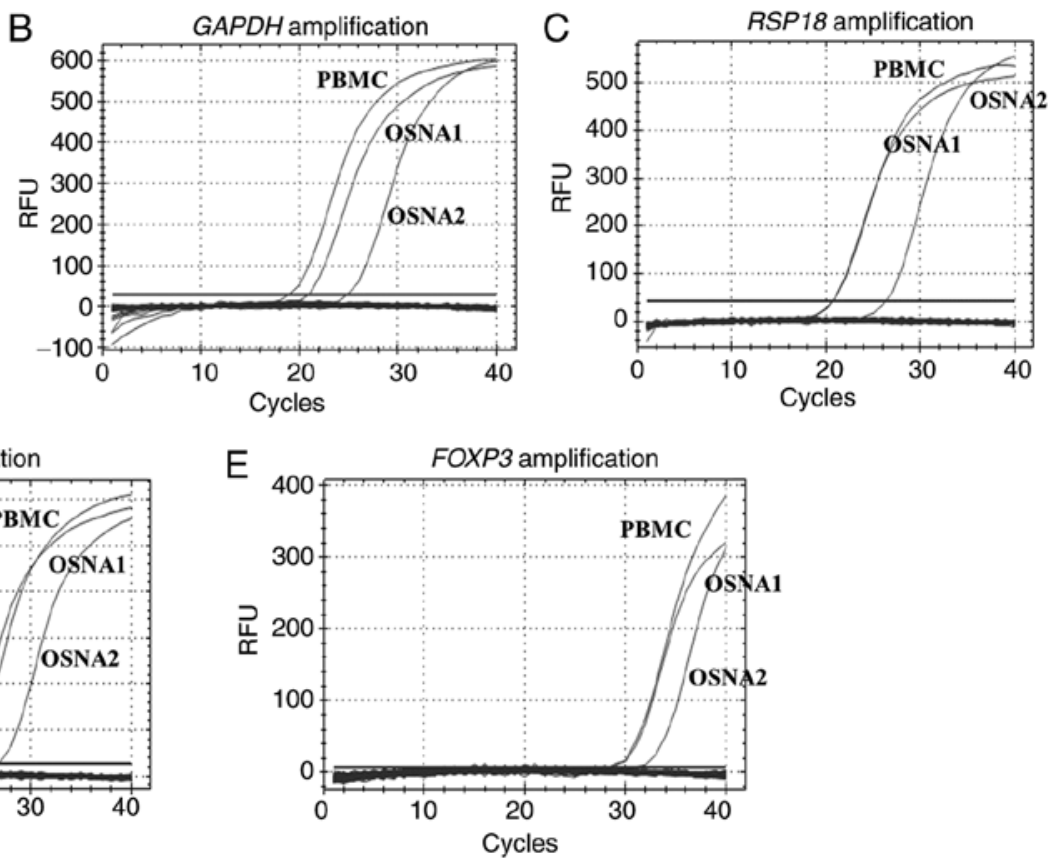

Figure 1. Quantitative PCR amplification curves for (A) B2M, (B) GAPDH, (C) RPS18, (D) CD4 and (E) FOXP3. OSNA, one-step nucleic acid amplification; $B 2 M, \beta 2$-microglobulin; GAPDH, glyceraldehyde-3-phosphate dehydrogenase; RPS18, ribosomal protein S18; $C D 4$, cluster of differentiation 4; FOXP3, forkhead box P3; PBMC, peripheral blood mononuclear cell; RFU, relative fluorescence unit.

Although the study of the SLN microenvironment using an OSNA assay is not feasible during the surgical procedure, it may provide important information regarding tumor-immune system interactions that could previously only be partially assessed by standard pathological evaluation (7-9).

This technical report was not designed to search for new markers and no comparisons were established between OSNA-positive and -negative patients, or regarding pathological or clinical characteristics. Furthermore, no comparisons were performed between gene expression levels in the three samples. The control that was used (PBMCs from a healthy donor) served as a positive control to access the feasibility of determining mRNA expression from OSNA samples. Lymph nodes comprise a complex cell population, different from PBMCs, and may not exhibit the same gene expression profile.

This new approach may help provide a combined test identifying both metastasis and new prognostic markers associated with immunoinflammatory response. We are currently performing further studies to support this hypothesis.

The results of the present preliminary study demonstrated that residual OSNA lysates could be used for further gene expression analysis, suggesting that this material could be employed as a bank of biological molecules for identifying novel biomarkers associated with the interplay between cancer and immune responses. However, future prospective studies should be performed to further evaluate the association between the gene expression profile and prognosis of patients with BC.

\section{Acknowledgements}

Not applicable.

\section{Funding}

The present study was funded by GenomePT-National Laboratory for Genome Sequencing and Analysis (grant no. POCI-01-0145-FEDER-022184) and national funds through the FCT - Foundation for Science and Technology, within the scope of the project UIDB/04539/2020.

\section{Availability of data and materials}

The datasets used and/or analyzed during the present study are available from the corresponding author on reasonable request.

\section{Authors' contributions}

HCS, MFD and IG conceived and designed the study; CR and HCS performed the RT-qPCR analysis; AG performed the OSNA assay; HCS and CR analysed the data and confirm the authenticity of all the raw data; CR and IG, with the participation of all other authors, wrote the original draft of the manuscript; CR, MFD and HCS reviewed and edited the manuscript. All the authors have read and approved that final manuscript.

\section{Ethics approval and consent to participate}

Informed consent was obtained from the participants or their legal representatives (CHUC-045-20), as recommended by the local Ethics Committee, following the tenets of the Declaration of Helsinki.

\section{Patient consent for publication}

Not applicable. 


\section{Competing interests}

The authors declare that they have no competing interests.

\section{References}

1. Cardoso F, Kyriakides S, Ohno S, Penault-Llorca F, Poortmans P, Rubio IT, Zackrisson S and Senkus E; ESMO Guidelines Committee. Electronic address: clinicalguidelines@esmo.org: Early breast cancer: ESMO Clinical Practice Guidelines for diagnosis, treatment and follow-up ${ }^{+}$. Ann Oncol 30: 1194-1220, 2019.

2. Jimbo K, Kinoshita T, Suzuki J, Asaga S, Hojo T, Yoshida M and Tsuda H: Sentinel and nonsentinel lymph node assessment using a combination of one-step nucleic acid amplification and conventional histological examination. Breast 22: 1194-1199, 2013.

3. Tsujimoto M, Nakabayashi K, Yoshidome K, Kaneko T, Iwase T, Akiyama F, Kato Y, Tsuda H, Ueda S, Sato K, et al: One-step nucleic acid amplification for intraoperative detection of lymph node metastasis in breast cancer patients. Clin Cancer Res 13 4807-4816, 2007.

4. Banerjee SM, Michalopoulos NV, Williams NR, Davidson T, El Sheikh S, McDermott N, Tran-Dang MA, Davison S and Keshtgar MR: Detailed evaluation of one step nucleic acid (OSNA) molecular assay for intra-operative diagnosis of sentinel lymph node metastasis and prediction of non-sentinel nodal involvement: Experience from a London teaching hospital Breast 23: 378-384, 2014.

5. Hunter-Smith AE and Rayter Z: One-step nucleic acid amplification: The possible value in assessing sentinel lymph node metastasis during mastectomy. Breast Cancer (Dove Med Press) 10: 13-21, 2018.

6. Brito MJ, Honavar M, Cipriano MA, Lopes J, Coelho H, Silva AR, Silva M, Guimarães S, Frutuoso A, Gomes A, et al: Molecular staging of patients with colon cancer. The C-Closer-II Study: A multicentre study in Portugal. Acta Med Port 31: 661-669, 2018.

7. Gibert-Ramos A, López C, Bosch R, Fontoura L, Bueno G, García-Rojo M, Berenguer M and Lejeune M: Immune response profile of primary tumour, sentinel and non-sentinel axillary lymph nodes related to metastasis in breast cancer: An immunohistochemical point of view. Histochem Cell Biol 152: 177-193, 2019.
8. Grigoriadis A, Gazinska P, Pai T, Irhsad S, Wu Y, Millis R, Naidoo K, Owen J, Gillett CE, Tutt A, et al: Histological scoring of immune and stromal features in breast and axillary lymph nodes is prognostic for distant metastasis in lymph node-positive breast cancers. J Pathol Clin Res 4: 39-54, 2018.

9. Shiota T, Miyasato Y, Ohnishi K, Yamamoto-Ibusuki M, Yamamoto Y, Iwase H, Takeya M and Komohara Y: The Clinical Significance of CD169-Positive lymph node macrophage in patients with breast cancer. PLoS One 11: e0166680, 2016.

10. Martín-Sánchez E, Pernaut-Leza E, Mendaza S, Cordoba A, Vicente-Garcia F, Monreal-Santesteban I, Vizcaino JP, De Cerio MJ, Perez-Janices N, Blanco-Luquin I, et al: Gene promoter hypermethylation is found in sentinel lymph nodes of breast cancer patients, in samples identified as positive by one-step nucleic acid amplification of cytokeratin 19 mRNA. Virchows Arch 469: 51-59, 2016.

11. Gallego Romero I, Pai AA, Tung J and Gilad Y: RNA-seq: Impact of RNA degradation on transcript quantification. BMC Biol 12: 42, 2014.

12. Bustin SA, Benes V, Garson JA, Hellemans J, Huggett J, Kubista M, Mueller R, Nolan T, Pfaffl MW, Shipley GL, et al: The MIQE guidelines: Minimum information for publication of quantitative real-time PCR experiments. Clin Chem 55: 611-622, 2009.

13. Livak KJ and Schmittgen TD: Analysis of relative gene expression data using real-time quantitative PCR and the 2(-Delta Delta C(T)) method. Methods 25: 402-408, 2001.

14. Fagerberg L, Hallström BM, Oksvold P, Kampf C, Djureinovic D, Odeberg J, Habuka M, Tahmasebpoor S, Danielsson A, Edlund $\mathrm{K}$, et al: Analysis of the human tissue-specific expression by genome-wide integration of transcriptomics and antibody-based proteomics. Mol Cell Proteomics 13: 397-406, 2014.

15. Lu L, Barbi J and Pan F: The regulation of immune tolerance by FOXP3. Nat Rev Immunol 17: 703-717, 2017. 